\title{
Agbiotech goes further afield
}

Stacy Lawrence

The total number of countries worldwide reportedly planting transgenic crops is now up to 21 , with soybeans, cotton and corn the major products. For the first time ever, last year witnessed more US field trial approvals for

transgenic crops enhanced for product quality than for herbicide-tolerant

\section{Global area of transgenic crops by country}

Iran, Portugal, France and The Czech Republic joined list of countries cultivating transgenic crops, with Brazil, Paraguay and India showing the greatest annual growth.

\section{Percentage change}

since 2004

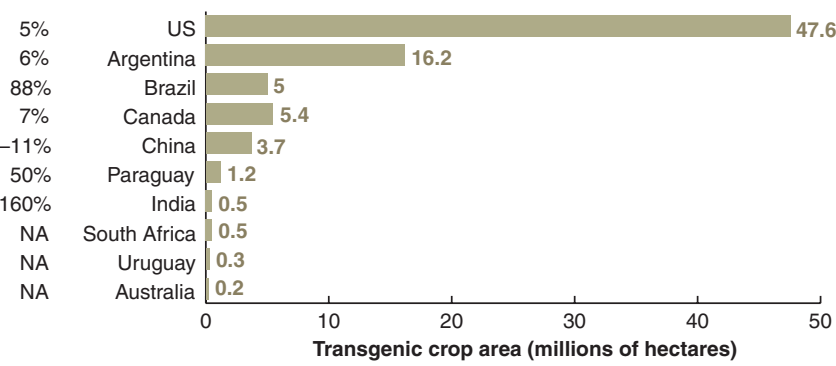

Source: International Service for the Acquisition of Agri-Biotech Applications

\section{Field trial permits by top US institutions}

Monsanto continues to dwarf all other companies when it comes to the volume of agbiotech trials.

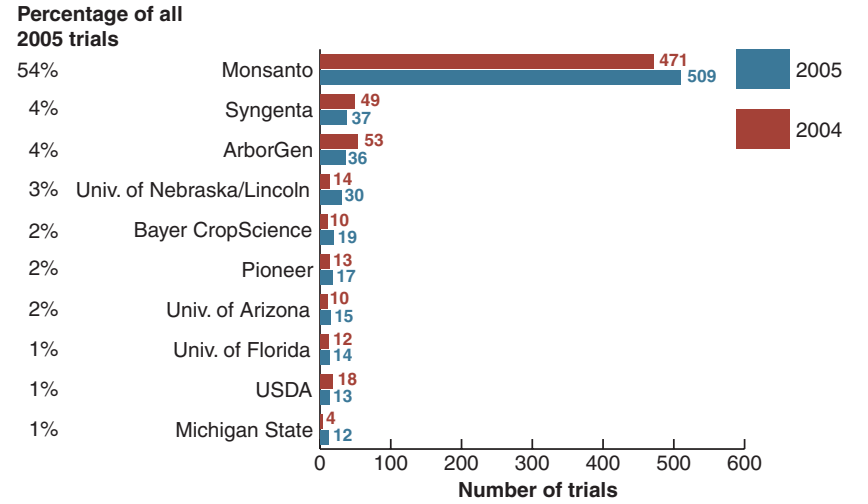

Source: Economic Research Service of the United States Department of Agriculture crops. Although field trials continue apace in the US, in Europe the number has fallen back to where it was in the early nineties, although a few countries, France, Portugal and the Czech Republic, started planting transgenic crops in 2005.

\section{Historical global area of transgenic crops}

Both the value and amount of land farmed with transgenic crops increased by $>10 \%$ last year.

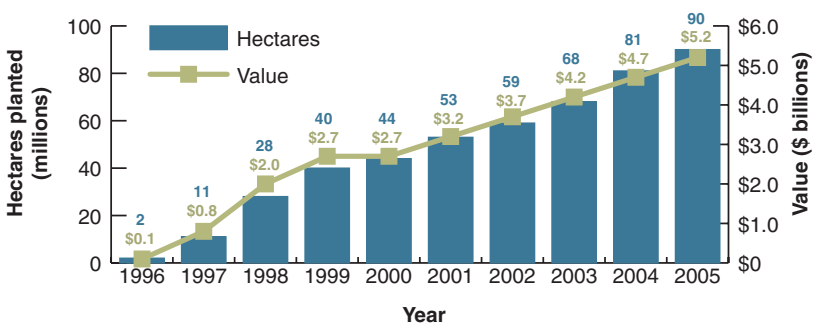

Source: Cropnosis, International Service for the Acquisition of Agri-Biotech Applications

\section{Phenotypes for approved US field trials}

Product quality superceded herbicide tolerance as a tested trait for the first time last year.

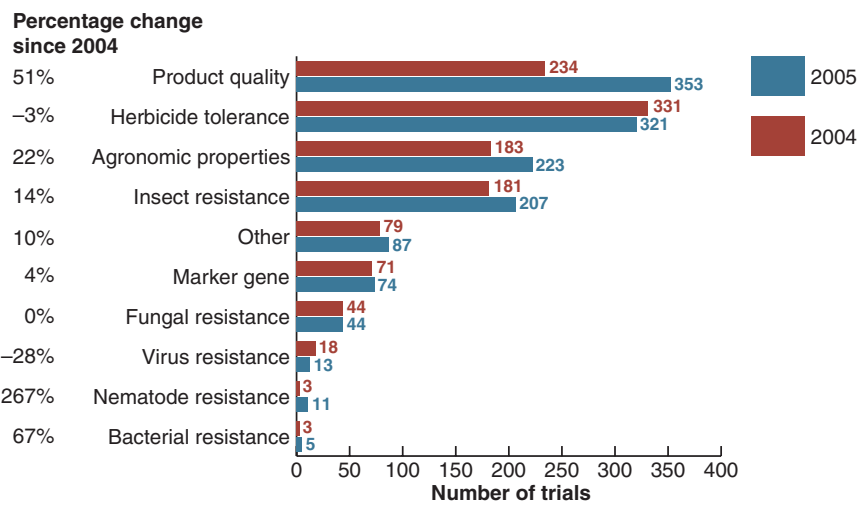

Source: Economic Research Service of the United States Department of Agriculture

\section{Number of European Union field trial notifications}

\begin{tabular}{|c|c|c|c|c|c|c|c|c|c|c|c|c|c|c|}
\hline & 1991 & 1992 & 1993 & 1994 & 1995 & 1996 & 1997 & 1998 & 1999 & 2000 & 2001 & 2002 & 2003 & 2004 \\
\hline Spain & - & - & 3 & 10 & 11 & 16 & 44 & 39 & 39 & 19 & 19 & 17 & 40 & 16 \\
\hline Sweden & - & - & - & - & 8 & 10 & 9 & 8 & 19 & 6 & 2 & 2 & 1 & 14 \\
\hline France & - & 1 & 35 & 57 & 69 & 91 & 72 & 70 & 64 & 34 & 17 & 3 & 17 & 11 \\
\hline Germany & - & 3 & 1 & 8 & 12 & 17 & 20 & 18 & 23 & 7 & 8 & 7 & 9 & 10 \\
\hline Netherlands & 4 & 15 & 9 & 25 & 16 & 10 & 14 & 19 & 5 & - & 19 & 4 & 4 & 7 \\
\hline Italy & - & & 5 & 19 & 43 & 50 & 46 & 43 & 51 & 18 & 5 & 9 & 2 & 4 \\
\hline Belgium & - & 26 & 16 & 17 & 11 & 7 & 7 & 6 & 8 & 16 & 5 & 8 & 1 & 2 \\
\hline Finland & - & - & - & - & 1 & 3 & 6 & 3 & 3 & 3 & 1 & - & - & 1 \\
\hline Iceland & - & - & - & - & - & - & - & - & - & - & - & - & - & 1 \\
\hline Poland & - & - & - & - & - & - & - & - & - & - & - & - & - & 1 \\
\hline United Kingdom & - & 16 & 17 & 23 & 37 & 27 & 25 & 22 & 13 & 25 & 12 & 5 & 8 & 1 \\
\hline Austria & - & - & - & - & - & 2 & 1 & - & - & - & - & - & - & - \\
\hline Denmark & - & 5 & 1 & 5 & 4 & 5 & 10 & 4 & 5 & 1 & - & - & - & - \\
\hline Greece & - & - & - & - & - & 1 & 5 & 7 & 6 & - & - & - & - & - \\
\hline Ireland & - & - & - & - & - & - & 2 & 2 & - & - & - & 1 & - & - \\
\hline Norway & - & - & - & - & - & - & - & - & 1 & - & - & - & - & - \\
\hline Portugal & - & - & 2 & 2 & 1 & - & 3 & 3 & 1 & - & - & - & - & - \\
\hline
\end{tabular}

For Austria, Finland and Sweden data is not available before 1995. Source: European Commission's Joint Research Center 